\title{
Do Students Value Feedback? Student Perceptions of Tutors' Written Responses
}

\author{
Melanie $R$ Weaver \\ Keywords \\ feedback, assessment, student perceptions
}

\begin{abstract}
The topic of feedback to students is an under-researched area, and there has been little empirical research published which focuses on student perceptions. This study explores student perceptions of written feedback and examines whether feedback received demonstrated a student-centred approach to learning. A multi-method approach of qualitative and quantitative data collection and analysis was used to survey 44 students in the faculties of Business and Art \& Design. Student responses show feedback is valued, but believed tutor comments could be more helpful. Survey results indicate that students may need advice on understanding and using feedback before they can engage with it. Content analysis of feedback samples and student responses uncovered four main themes of feedback considered unhelpful to improve learning: comments which were too general or vague, lacked guidance, focused on the negative, or were unrelated to assessment criteria. It is suggested that by focusing on messages conveyed by their writing, providing feedback set in the context of assessment criteria and learning outcomes, and by ensuring that it is timely, tutors could greatly improve the value of feedback.
\end{abstract}

\section{Introduction}

It is accepted in academic circles that feedback is an essential component in the learning cycle, providing for reflection and development. Alerting students to their strengths and weaknesses can provide the means by which they can assess their performance and make improvements to future work. Despite recognising that timely and helpful feedback to students is an important aspect of learning, however, it is not an area that has been widely addressed in the academic research. Focus has been primarily on content analysis of feedback, and providing advice on writing effective feedback (e.g. Brown et al 1997, Race 2001, Mutch 2003). Academics complain that feedback does not work, and anyway students are more interested in their grade or mark and pay little attention to feedback. Whilst those views are based partly on anecdotal evidence, at least two studies support and may have influenced their views. Wojtas (1998) reported on the research findings in one university, suggesting that some students were concerned only with their mark and not the feedback. Even when given feedback, however, Fritz et al (2000) believed that it does not improve learning. In conducting experiments to test students' memory recall and explore whether performance would be improved with feedback, it was concluded that feedback was not effective in improving learning. As the findings relate only to students' recall of information, however, it has yet to be established that feedback is not effective in improving other, higher level cognitive skills.

Mutch (2003) calls for further research into how students receive and respond to feedback, which was the seed that planted the idea for this study. In addition, the last decade has seen a 'paradigm shift' (Rust, 2002) towards a more student-centred approach to education. But until we more fully understand the views and responses of students, education cannot hope to be truly student-centred. The aim of this paper, therefore, is to carry out both a quantitative and qualitative study, which focuses on student attitudes, beliefs and perceptions in relation to the written feedback received by tutors. The study will attempt to examine four questions:

1. Do students understand written feedback by tutors?

2. What are students' perceptions of written feedback?

3. What do students perceive as helpful versus unhelpful feedback? 


\section{Supporting Literature}

A student's previous experience (Ramsden 1992) and their intellectual maturity (Perry 1970) will play a large part in their approach to learning and therefore the extent to which they are able to engage with tutor comments. Hounsell's (1987) qualitative study of second year undergraduate students discovered two divergent student conceptions of what constituted an essay; one oriented towards the establishment of meaning, and one oriented towards structure and content. These conceptions are very similar to what has become known as 'deep' and 'surface' approaches to learning (see Ramsden 1992). The implication is that the value of feedback depends upon the student's particular conception; students who do not yet share a similar understanding of academic discourse as the tutor would subsequently have difficulty in understanding and using the feedback.

These findings are supported by Lea and Street's (2000) qualitative study, which examined students' interpretation of feedback comments. Because of the implicit assumptions held by both students and tutors about what constitutes subject knowledge, they determined that students often interpreted comments differently from what was intended. For example, the comment "evidence of some wider reading shown", implies that the tutor expected wider reading of the subject than was evident. Students may misread this comment, literally interpreting it as confirmation that they had carried out the 'wider reading' required.

In some cases, there may be a more simple explanation. Maclellan (2001) also questioned students' conception of feedback, but suggested that improvement in learning occurs when students perceive feedback as enabling learning, and not just as a judgement on their level of achievement. Corroborating this view was the research study reported by Wojtas (1998), claiming that many students improved their work once they understood the purpose of feedback and assessment criteria.

To address the lack of quantitative studies, Hartley \& Chesworth (2000) administered a questionnaire that sought to understand student perceptions of feedback. They found that students frequently have difficulty interpreting the requirements of different subjects and of different tutors. This supports the argument that some students' level of understanding is insufficient to make sense of implicit as well as explicit messages. In these cases, feedback may not be enough to improve students' learning (Hounsell 1995).

The language used in responding to feedback also affects the way in which a student receives written feedback. Much advice to academics about how to write feedback concerns the language to be used. For instance, judgmental statements which allow no room for manoeuvre, (e.g. 'good report', 'fails to answer the question', 'poor effort') are seen as unhelpful and, particularly if critical or dismissive, can cause anger or hurt, resulting in students becoming unreceptive to tutor comments (Boud 1995, Hounsell 1995). Lea and Street (2000) argue that comments containing unmitigated statements and imperatives caused difficulty in interpretation, which confused or upset students, and the opportunity for learning was thus lost.

In addition, if feedback is to be of any use to students, it is important to consider what messages are being conveyed. The way in which comments are worded, and the nature of the message, is ultimately shaped by tutors' values, beliefs and understandings. Ivanič et al's (2000) analysis of feedback identified different response styles and suggested they were dependent upon tutors' beliefs about their purpose in providing feedback. Biggs' (1999) theory that tutors hold three conceptions or 'levels' of teaching suggests that what the tutor focuses on as most important affects the feedback response. Tutors at levels one and two may use feedback to provide quantitative comments about knowledge - evaluating the work's 'correctness', or justifying the mark given, whereas at level three, tutors are likely to provide more qualitative comments on the process of writing, focused on guiding and motivating. This echoes Hounsell's (1987 p 118) study, which concluded that feedback which is content rather than process driven "is unlikely to connect". 
As previously mentioned, a received message has the potential to be misinterpreted. It is commonly accepted that poorly written feedback might be taken personally by students, and lead to defensiveness and loss in confidence. "We judge too much and too powerfully, not realising the extent to which students experience our power over them" (Boud 1995, 43). Self-esteem, it is believed, is affected by receiving negative or unexpected feedback. A qualitative study by Young (2000) suggests, however, that this should be considered from the opposite perspective: it is the student's level of self-esteem that affects the messages they receive - both positive and negative. Those with low self-esteem tended to view all feedback as a judgement of ability, whilst those with high self-esteem did not.

High and medium self-esteem students tended to see feedback as something they were able to act on and make use of; students with low self-esteem were more likely to feel defeated and consider leaving the course (Young 2000 p 415).

Young's conclusion that the tutor must have an understanding of each student's needs before providing feedback is commendable, but sadly may prove to be unrealistic in the move towards modularity and increasing class sizes.

Different messages about institutions' values and beliefs are also conveyed by the style of tutor response. Ivanič et al (2000) found that messages suggest absolute, departmental, or functional conventions as well as reinforce institutional orthodoxies. The educational context is also believed to affect students' perception of feedback. Falchikov (1995) commented on how the educational context has presented teachers with a dichotomy in giving feedback: on the one hand wishing to provide timely and useful feedback but on the other, feeling the pressure of reducing the amount of feedback due to increased student numbers and hence workload. Lea and Street (2000) found that institutional procedures, such as the change to modularity, could negatively affect students' understanding and use of feedback. Most of the coursework in a modular system is summatively assessed, so not only do students have no opportunity to act upon feedback in order to improve upon a piece of work, but by the time they do receive their feedback, the module has already been completed. This is supported by Hartley and Chesworth (2000), who found that $59 \%$ of students in their study responded that feedback was given too late to be helpful because of being received after module end. Atkins (1995) proposes that when the change to modularisation means more summative rather than formative assessment, it may be counterproductive to the development of students' academic knowledge and skills.

Formative assessment is used in order to provide feedback for the purpose of development, but in practice many universities, in an attempt to reduce the burden of staff workload, use coursework assessment to provide summative as well as formative feedback (Brown et al 1997). Both Atkins (1995) and Brown et al (1997) suggest that formative feedback on coursework assessment may cease to be of value when combined with summative assessment. Much of this hinges on an institution's assessment strategy. The QAA's Code of Practice on Assessment of Students (2000 p 10) states that "institutions should ensure that appropriate feedback is provided to students on assessed work in a way that promotes learning and facilitates improvement". Now that QAA subject reviews have uncovered inconsistent assessment practices as the most frequent low scoring area (Rust, 2002), more consideration may be given by higher education institutions to ensuring 'appropriate' feedback. Only then can the question of whether students act upon feedback to advance their learning be properly researched.

\section{Analysing Student Perceptions}

Approximately 170 Business and 340 Art \& Design (hereafter termed 'Design') students were surveyed by questionnaire; 24 and 20 students respectively replied for 
a total response rate of eight percent. In addition, preliminary group discussions with 22 students, and responses from the open-ended questions in the survey, provided the qualitative data.

\section{Quantitative Findings}

Demographic information for the students in both Business and Art \& Design is summarised in Table 1 below.

\section{TABLE 1 HERE}

\section{1) Understanding Feedback}

Respondents were asked to indicate how confident they were in understanding some common phrases used in written feedback. Table 2 indicates the respondents' confidence by percentage. (One student did not complete four of the items.)

The students were asked to rate seven items on a four-point scale of 'very confident' to 'very unsure'. All of the Business students showed confidence in understanding the first item, and a clear majority were confident with the second. The remaining five items indicated that between $21 \%$ and $41 \%$ of students lacked confidence in their understanding. Of those five items, half of the first year students were unsure. Second year students were more confident, with only the final two phrases indicating a couple of students to be slightly unsure. However, between $20 \%$ and $30 \%$ of the third year respondents showed a lack of confidence in the final three items. Business School tutors regularly use these phrases relating to cognitive skills. Design students showed a greater lack of confidence overall in the meaning of the phrases in comparison with Business students. However, these phrases were drawn from examples of discourse used in the Business discipline, and it was realised that they may not be representative of the academic discourse used in the Design faculty. Therefore, Design findings have been disregarded for this part of the study.

\section{TABLE 2 HERE}

The students were asked to choose a response between 'always' and 'never' to describe how often each of four criteria were observed in feedback they have received. Table 3 shows, by percentage, how the students responded. Broadly speaking, the majority of respondents felt that feedback was clear and readable, although a quarter of Business students did answer 'sometimes'. The results show, however, that Business lags behind Design in relating feedback both to learning outcomes and to assessment criteria. Business students responded that feedback 'sometimes' to 'never' related on $62 \%$ and $41 \%$ occasions respectively, in comparison with $35 \%$ and $30 \%$ for Design. In addition, the majority of Business and a large minority of Design respondents reported that feedback was appropriate to the mark 'sometimes' or 'seldom'. This could indicate that feedback was often not related to the learning outcomes and/or assessment criteria.

\section{TABLE 3 HERE}

Respondents were then asked whether they had received guidance on how to understand and use feedback. Table 4 shows the percentages of the student responses. On average, half of the students claimed that no guidance had been received, and only a few respondents believed that guidance had been received whilst attending their course of study. These results do suggest that more guidance in interpreting and using feedback is needed; many students may lack the understanding necessary to accurately interpret academic discourse. 


\section{2) Perceptions on the Use and Helpfulness of Feedback}

The second section of the survey contained a number of attitude statements related to student perceptions of feedback, which students were asked to rate between 'strongly agree' and 'strongly disagree'. It is to be noted that not all attitude statements add up to 100 percent, as there were a number of 'unsure' responses that were not included. A selection of items and their percentage responses have been included in Table 5.

\section{TABLE 5 HERE}

An overwhelming majority of students from both Business and Design agreed with the statements 'constructive criticism is needed to know how to improve' and 'feedback is helpful to explain gaps in knowledge and understanding'. A high majority also agreed that tutors do not provide enough feedback, and that more positive feedback should be given. The item showing the closest split in responses was the negative statement that feedback rarely provided students with useful suggestions for improvement, to which a small majority agreed. There was also general agreement that feedback comments were related to assessment criteria (62\% of Business and $65 \%$ of Design students) which correlates with results shown in Table 3 (58\% and $70 \%$ respectively).

The only significant difference between Business and Design student responses was in the negative statement 'feedback given at the end of the module is not useful', to which $71 \%$ of Business students but only $30 \%$ of Design students agreed. This finding highlights the difference in course design and consequent feedback practice between the Business and Design faculties. Business students attend six modules per half year, traditionally delivered by lecture and seminar. Each module requires one, or in some cases, two assessments, which are held mainly at the end of the module. Hence, feedback on coursework is often received after the module is completed and is, as a result, primarily summative. On the other hand, Design students attend four modules per half year for the first two years, and three modules for the final year. Teaching is through a variety of methods including workshops and tutorials, and tends to have two or three staggered assessments, so formative verbal and written feedback is received throughout the term. Final year students receive much individual tuition through tutorials.

The final set of attitude statements relates to how the students perceived the effectiveness of the feedback they received over the past year. Table 6 highlights responses, by percentage, to a selection of key items. Many of the items can be seen to affect student motivation. For example, although a large majority of students believed that feedback was too brief or general to be helpful, and only half believed that feedback encouraged them to improve their performance, they confirmed that when given suggestions for improvement, they were acted upon. They also disagreed with the statement 'I have good intentions, but forget suggestions for improvement next time I do coursework', and 'I have ignored negative or critical feedback', suggesting that constructive criticism is valued by students, and has motivated them to improve. On statements related to confidence and self-esteem, an overwhelming majority agreed that positive comments had increased their confidence, and few students thought about giving up when receiving negative feedback. Most students disagreed that receiving negative feedback caused feelings of despair, although $25 \%$ of Design students did agree, as compared to only $8 \%$ of Business students. The reason for this difference may be due to there being slightly more first year students in Design than in Business. A small majority also disagreed that negative feedback caused them to feel angry or demoralised. A pleasing finding was that the majority of respondents agreed with the statement 'feedback had helped me to reflect on what I have learned', although Business students did not agree to the extent of Design students (63\% and $70 \%$ respectively). 


\section{Qualitative Findings}

During group discussions, students were asked to provide samples of written feedback they had received, and explain their perceptions of helpful versus unhelpful comments. Comments were analysed using content analysis (Neuman 1994) and the data coded in order to identify categories. A number of themes emerged, the four most frequent being presented sequentially below.

\section{1) Too general or vague}

The majority of respondents identified unhelpful feedback as that which was too general and lacking in detail, as highlighted by the following remarks.

two word notes at the side of the report didn't help much. we usually had a tick or something circled to say something was wrong. Usually we could work out what went wrong but some analysis of what was lacking would have helped in future assessments.

although there was feedback, it was not particularly detailed.

This is supported by tutor comments obtained from feedback samples: "...you have got the important stuff right", "there are certain sections which could have been better supported...", and "a sound answer generally".

One respondent also identified that insufficient detail could be due to the lack of time which tutors have available for writing feedback.

I think that tutors are perhaps pushed for time and I get the impression that many rush feedback. It would be useful if there was more detail given.

\section{2) Lack of guidance}

When asked to provide examples of unhelpful feedback, the majority of students identified this as comments that did not contain suggestions for improvement. They had expectations about receiving guidance that were not being met. The following comment is representative of these views.

...I got told that a piece of work was more like an essay than a literature review. This is not helpful as it does not tell me what should be contained in a literature review or how it should be presented.

Some of the comments, such as that above, also highlight an imbalance in course design; although originally the course would have been designed with each module in alignment, when modules are changed or removed, it can lead to inconsistencies. In this case, the removal of a preceding module which provided tutoring in literature reviews meant the students may not have had sufficient guidance prior to their assessment. In addition, this may also be a reflection of a difference in assumptions between lecturer and student; lecturers may have had an assumption of the level of understanding that students had not yet reached, as was suggested by Ramsden (1992).

In the main, respondents confirmed that feedback containing constructive comment was necessary for improvement. When respondents were asked to give specific examples, they perceived helpful feedback to have included both diagnosis and guidance. 
Feedback showing how a report could be improved in specific places was very useful, [as I] knew exactly how and where improvements could be made.

[The feedback] set out a list of all the things that I had done well in my coursework and also told me why my grade could not have been any higher, i.e. to receive a higher grade I would have needed to include $x, y$ and $z$.

Analysis of the feedback samples provided by the students supported their criticism that guidance was not prevalent in written comments. Some respondents identified that for feedback to be helpful, it must contain general advice that can be used for future work. Of the analysed feedback containing guidance, most comments were specific to that particular essay - as if the student had presented a draft that could be resubmitted, although it was a final piece of work. The few feedback artefacts identified as 'helpful' by the students did contain general guidance comments.

A number of respondents complained that they did not receive guidance when high marks were achieved. The feedback samples generally supported this view, although some tutors did include diagnosis that implied guidance, such as "the lack of a conclusion...let it down".

\section{3) Focus on the negative}

A common response from the surveyed students highlighted the tendency for tutors to comment mainly on weaknesses. In replying to how they would like to see feedback improved, students identified a balance between positive and negative comments as important, and described how both types of comment made them feel.

The slightest good comment made makes a student feel good and tutors need to remember this.

Encourage positive comments as well as negative. Too many negative comments are demoralising.

There is nothing wrong with critical evaluation, but students do need positive feedback on where they have done well to give them confidence.

Analysis of feedback artefacts found that overall, the writing showed a pattern of positive-negative or positive-negative-positive comments. However, one respondent's comment, that his feedback often contained ".... lot of negative criticism for one aspect of a project and little else but 'good' for the other aspects" was supported by the feedback analysis. Positive comments tended to be vague, such as "some reasonable reflection", "good analysis", "a sound answer generally", whilst the criticisms were more comprehensive. Some feedback contained no positive comment at all; for example a report which received a high 2:1 mark contained feedback which began, "Potentially a first class report but...", then proceeded to identify weaknesses, and ended with "Inconsistent questionnaire".

4) Unrelated to assessment criteria

Students in class discussions and on the survey indicated that comments were not set in the context of assessment criteria.

Feedback I received from my coursework picked up on things I had missed, but the things mentioned were not part of the assessment criteria. 
Analysis of the feedback artefacts supported these observations. With one exception, the collection of samples contained no specific reference to assessment criteria; they were at best implicit and at worst, entirely absent. Some respondents noted that their mark and feedback were not matched, which suggests that the comments made were not linked to assessment criteria. During class discussions, students commented that they were not given any assessment criteria to work to, only suggestions of what constituted a 'good' essay or report. This negatively affected the helpfulness of the subsequent feedback.

\section{Discussion}

The majority of research on the topic of feedback has focused on academic perspectives and written artefacts. Limited research has focused on student perceptions of the value and usefulness of feedback. The focus of this study has been to explore the attitudes, beliefs and perceptions of students regarding written feedback with a view towards establishing whether, in practice, feedback does effect improvement in learning. Two studies were conducted, using complementary approaches of qualitative and quantitative data collection and analysis.

The first question this study aimed to answer was whether students understood the feedback they received; this was carried out through a quantitative survey. Although this area was examined very briefly, the findings do suggest that quite a number of students are unsure of some of the common terms used by tutors. As $50 \%$ of students believed they had not received guidance on how to read and use feedback, it is logical to conclude that misinterpretation will occur, which will affect students' response to feedback. In addition, it is likely that academics will hold assumptions about students' ability to interpret their comments accurately, in line with the findings on academic discourse (e.g. Lea \& Street 2000, Hounsell 1995). It does raise a concern that a sizable minority of students may be progressing through their course of study without a clear understanding of what is required to improve their expressed cognitive skills.

The remaining questions of this paper sought to identify student perceptions of written feedback and how helpful they perceived it to be, together with suggestions on how the value of feedback could be increased. The two studies revealed that students wholeheartedly recognise the value of feedback in improving their learning, but their comments imply that feedback is not as effective as it could be. One of the main issues that arose out of the research was students' belief that feedback was too vague or general to be of use, a belief backed up by the artefacts examined. Whilst a popular retort is that tutors do not have the time needed to be more thorough, the fact remains that students feel short-changed, and understandably upset. Students indicated that they were motivated to improve when they received constructive criticism, although such guidance appeared to be rare, particularly for the higher achieving students. Although a large majority of students felt positive feedback to be very important and confirmed it increased their confidence, the evidence showed a decided lack of positive comments. They also clearly identified their need for more of a balance between positive and negative comments, in order to ensure that feedback would motivate rather than discourage. Although there was no evidence to support the view that negative feedback damages self-esteem, the survey respondents were volunteers, suggesting committed and confident students. It is quite possible, therefore, that most of them had medium to high self-esteem, which would have affected their responses, according to Young's (2000) theory. Further limitations are discussed below.

A number of students also perceived unhelpful feedback as that which did not relate to assessment criteria, or to the mark received. This was also substantiated by the feedback samples analysed. Two possible reasons are suggested as to why this might be so. Firstly, feedback that contains vague or general comments provides few clues to students about the features of their work that met assessment criteria and that which fell short. Secondly, it appears that a number of tutors are not yet providing specific assessment criteria, or information on how the mark is computed; general instructions, often verbal, about what a 'good' piece of work should contain 
are being provided instead. Vague or non-existent criteria cause confusion about what is expected; subsequent feedback that is also vague and does not refer to specific criteria cannot match expectations with performance. Consequently the students will not receive beneficial information about progress. This is supported by research, as discussed in Miller et al (1998), that found when written assessment criteria was provided before assessment and used for subsequent marking, both tutor and student benefits: the tutor in considering all aspects of the coursework when marking, the student in understanding both the reasons for the mark and the good and weak aspects of the assessed work.

Much of the above-noted results also corroborate the findings of QAA subject reviewers in UK higher education institutions. For both Business and Design subjects, reviewers have noted inconsistencies in the clarity and use of assessment criteria, and believed that students "could be briefed more effectively about both the requirements of assignment tasks and the computation of grades." (QAA 2001 p 4). Appropriate and timely feedback was considered to be the weakest area for more than forty percent of Business institutions, with feedback noted as being provided too late to be useful. This was only a minor point across the Art \& Design institutions, because of their tradition of oral feedback through tutorials (QAA 2000).

This tradition of oral feedback is one of the differences in modular and course design which resulted in a divergent response by Business and Design students. There were indications that Business students received feedback too late to be helpful on a number of occasions, although they maintained that comments were still read and suggestions for improvement remembered. Assessment practices which focus on end-of-module assessment and written feedback - in reality, summative assessment - cannot effectively help to develop knowledge and skills, as previously discussed (e.g. Atkins 1995, Brown et al 1997). Until the Business School amends their assessment policy, it is up to tutors to employ the necessary time management strategies to ensure feedback is still useful, such as those suggested by Brown et al (1997).

When interpreting the results of these studies, consideration must be given to the quality and reliability of student responses; that is, whether the students have ticked boxes in a superficial manner to complete the survey quickly. The low number of 'unsure' or incomplete responses ( $3 \%$ of the total answers) does suggest that students considered the question and expressed definite views.

The validity of the study must also be considered. The sample size for the survey was small, as only 44 students took part, making the response rate $14 \%$ for Business and 6\% for Design, much lower than expected for this type of survey. The reason for the low response was undoubtedly due to the timing of the survey: all questionnaires were emailed at the completion of the taught curriculum and the commencement of the exam revision period. Although the sample size is satisfactory for a qualitative research study, the low response means that the student perceptions are not necessarily representative of the entire student population - the respondents may have been more committed to their studies, or more motivated to give their views than their colleagues, for example. This survey was never intended to provide definitive answers, but rather to explore an under-researched area and suggest some initial findings. A larger study would be required to validate these findings, particularly with regard to motivation and self-esteem aspects. Nevertheless, the data has been triangulated by the multi-method approach, and also correlated by previous studies and government findings. Taking this into account, some general conclusions can be made from this study.

\section{Concluding remarks}

There may be some truth to the claim by some academics that students do not 'bother with' feedback, but in light of these findings, this may be because either the feedback does not contain enough to guide or motivate students, or they have insufficient understanding of academic discourse to interpret comments accurately. Although it is evident that many tutors do try to provide helpful and detailed feedback, it also appears that this practice is inconsistent. Some academics appear to lack the 
knowledge of how to provide effective feedback, but in considering all of the resources available on this subject, it is a rather weak defence. Others may simply be overloaded and feel they cannot find the time to provide more thoughtful feedback. Finally, there will always be those who remain cynical about the entire process of student learning in general and the purpose of feedback in particular.

Is it cause for concern that students are noticing the time pressures of lecturers? Students are increasingly perceiving themselves to be customers, with certain service expectations; if those expectations are not met, and the number expressing dissatisfaction increases substantially, it could have an effect on the reputation of a course and ultimately the intake of students.

To provide students with the best opportunity for improving their knowledge base and develop necessary skills, it is important that tutors become aware of their response styles and the possibility of students misinterpreting academic discourse, which will affect the usefulness of feedback. By reviewing their beliefs on the purpose of feedback, examining the language they use and messages they convey, as suggested in the reviewed literature (e.g. Hounsell 1987, Lea and Street 2000, Ivanič et al 2000), a tutor's feedback will have a better chance of connecting with the student and addressing their main concerns. For example, the results from this study suggest that an important step towards making feedback more effective is through providing a better balance between positive and critical feedback. Tutors need to direct their energies towards providing appropriate guidance and motivation to students rather than simply diagnosing problems and justifying the mark.

In terms of the educational context, this study has shown some justification for the concerns of modularisation (Atkins 1995, Brown et al 1997) and the trend towards providing feedback after course completion, thus limiting its usefulness (Hartley \& Chesworth 2000, Wolf 2004). Because of the structural or resource constraints, it may never be possible to find a perfect solution, although more of a course focus should help to avoid inconsistencies in alignment. Ensuring that assessment is aligned to the curriculum is the main principle behind encouraging deeper learning (Miller 1998, Biggs 1999). Tutors can ensure that their feedback is constructive and clearly set in the context of learning outcomes and assessment criteria, which guides the students on how to improve their performance. These strategies may help to improve the communication between tutor and student, and go some way towards developing a student-centred approach to learning and teaching.

\section{References}

ATKINS, M. (1995) What Should we be Assessing? in: KNIGHT, P. (Ed) Assessment for Learning in Higher Education, (London, Kogan Page).

BIGGS, J. (1999) Teaching for Quality Learning at University, (Buckingham, Open University Press).

BROWN, G., BULL, J. \& PENDLEBURY, M. (1997) Assessing student learning in higher education, (London, Routledge).

BOUD, D. (1995) Assessment and Learning: Contradictory or Complementary? in: KNIGHT, P. (Ed) Assessment for Learning in Higher Education, (London, Kogan Page).

FALCHIKOV, N. (1995) Improving Feedback to and from Students, in: KNIGHT, P., (Ed) Assessment for Learning in Higher Education, (London, Kogan Page).

FRITZ, C., MORRIS, P. \& BJORK, R. (2000) When further learning fails: Stability and change following repeated presentation of text. British Journal of Psychology, 91, pp. 493-511. 
HARTLEY, J \& CHESWORTH, K (2000) Qualitative and Quantitative Methods in Research on Essay Writing: No One Way, Journal of Further and Higher

Education, 24(1), pp.15-24.

HOUNSELL, D. (1987) Essay Writing and the Quality of Feedback, in:

RICHARDSON, J., EYSENCK, M. \& PIPER, D. (Eds) Student Learning: Research in Education and Cognitive Psychology, (Milton Keynes, Open University Press).

HOUNSELL, D. (1995) Marking and Commenting on Essays, in: FORSTER, M. HOUNSELL D. \& THOMPSON, S. (Eds) Tutoring and Demonstrating: A Handbook, (Sheffield, HESDA).

IVANIČ, R., CLARK, R. \& RIMMERSHAW, R. (2000) What am I Supposed to Make of this? The Messages Conveyed to Students by Tutors' Written Comments, in: LEA, M. \& STIERER, B. (Eds) Student Writing in Higher Education: new contexts, (Buckingham, Open University Press).

LEA, M. \& STREET, B. (2000) Student Writing and Staff Feedback in Higher Education: An Academic Literacies Approach, in: LEA, M. \& STIERER, B. (Eds) Student Writing in Higher Education: new contexts, (Buckingham, Open University Press).

MILLER, A., IMRIE, B. \& COX, K. (1998) Student Assessment in Higher Education: a handbook for assessing performance, (London, Kogan Page).

MUTCH, A. (2003) Exploring the practice of feedback to students, Active Learning in Higher Education, 4(1), pp. 24-38.

NEUMAN, W. (1994) Social Research Methods: Qualitative and Quantitative Approaches, (Massachusetts, Simon \& Schuster).

PERRY, W.G. (1970) Forms of intellectual and ethical development in the college years: a scheme. New York: Holt, Rinehart and Winston.

QUALITY ASSURANCE AGENCY (QAA) (2001) Business and Management Subject Overview Report, available at: http://www.qaa.ac.uk/revreps/subjrev/ All/q05_2001.pdf [accessed June 2003].

QUALITY ASSURANCE AGENCY (QAA) (2000) Code of practice for the assurance of academic quality and standards of higher education. Section 6 : Assessment of Students. Available at: http://www.qaa.ac.uk/public/cop/ copaosfinal/COP_AOS.pdf [accessed June 2003].

RACE, P. (2001). The Lecturer's Toolkit, $2^{\text {nd }}$ edition (London, Kogan Page).

RAMSDEN, P. (1992) Learning to Teach in Higher Education, (London, Routledge).

RUST, C. (2002) The impact of assessment on student learning, Active Learning in Higher Education, 3(2), pp. 145-158.

WOLF, A. (2004) 'Have you noticed how the idea has spread that academics might be "overteaching" at the expense of activities such as packing in more students?' Times Higher Education Supplement, November 192004.

WOJTAS, O. (1998) Feedback? No, just give us the answers. Times Higher Education Supplement, September 251998. 
YOUNG, P. (2000) 'I Might as Well Give Up': Self-esteem and Mature Students' Feelings About Feedback on Assignments, Journal of Further and Higher

Education, 24(3), pp. 409-418. 